\title{
Packaging free software chemistry programs in Debian GNU/Linux: past, present and future
}

\author{
Michael Banck ${ }^{1,2}$ \\ From 7th German Conference on Chemoinformatics: 25 CIC-Workshop \\ Goslar, Germany. 6-8 November 2011
}

Started in 1993, the Debian project is one of the oldest Free Software projects. Due to its volunteer nature, specialists from all fields contribute to the Debian GNU/ Linux distribution, which includes more than 30000 packages. The Debian packaging policy, its advanced package management system and the conservative release process lead to a stable basis which is ideal for customized environments like scientific research.

The Debichem project [1] has been packaging and maintaining chemical software compliant with the Debian Free Software Guidelines (DFSG) [2] since 2006. Currently, 35 Free Software package are directly maintained by the Debichem team and 10 more are part of Debichem but maintained by others.

At the core of Debichem are the cheminformatics packages OpenBabel [3], CDK [4] and RDKit [5]. They provide file format conversion, 3D coordinate generation, molecular descriptors and fingerprints, stereochemistry prediction, conformation generation and searching, forcefields and more.

Besides those, a variety of $2 \mathrm{D} / 3 \mathrm{D}$ visualization and molecular modelling programs, as well as ab initio, semi-empirical and molecular dynamics codes are packaged by the Debichem in Debian.

Future work will include packaging of cinfony [6], a python module which presents a common API over OpenBabel, CDK and RDKit.

\section{Author details}

'Department of Chemistry, Technische Universität München, Lichtenbergstrasse 4, D-85747 Garching, Germany. ${ }^{2}$ Debian Project.

Published: 1 May 2012

\footnotetext{
Correspondence: michael.banck@ch.tum.de

'Department of Chemistry, Technische Universität München,

Lichtenbergstrasse 4, D-85747 Garching, Germany

Full list of author information is available at the end of the article
}

\section{References}

1. [http://alioth.debian.org/projects/debichem]

2. [http://www.debian.org/social_contract\#guidelines].

3. O'Boyle NM, Banck M, James CA, Morley C, Vandermeersch T, Hutchison GR: Open Babel: An Open Chemical Toolbox. J Cheminf 2011, 3:33.

4. Steinbeck C, Han Y, Kuhn S, Horlacher O, Luttmann E, Willighagen EL: The Chemistry Development Kit (CDK): An Open-Source Java Library for Chemo- and Bioinformatics. J Chem Inf Comput Sci 2003, 43(2):493-500.

5. [http://rdkit.org/]

6. O'Boyle NM, Hutchison GR: Cinfony - combining Open Source cheminformatics toolkits behind a common interface. Chem Cent J 2008, 2:24.

\section{doi:10.1186/1758-2946-4-S1-F4}

Cite this article as: Banck: Packaging free software chemistry programs in Debian GNU/Linux: past, present and future. Journal of Cheminformatics 2012 4(Suppl 1):F4.

\section{Publish with ChemistryCentral and every scientist can read your work free of charge \\ "Open access provides opportunities to our colleagues in other parts of the globe, by allowing anyone to view the content free of charge." W. Jeffery Hurst, The Hershey Company. \\ - available free of charge to the entire scientific community - peer reviewed and published immediately upon acceptance \\ - cited in PubMed and archived on PubMed Central \\ - yours - you keep the copyright \\ Submit your manuscript here: \\ http://www.chemistrycentral.com/manuscript/

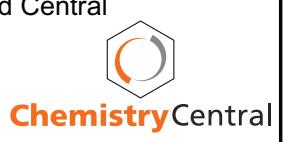

